\title{
ST2 in Stable and Unstable Ischemic Heart Diseases
}

\author{
A. Mark Richards, $\mathrm{MD}^{\mathrm{a}, \mathrm{b}}$, , Salvatore Di Somma, $\mathrm{MD}^{\mathrm{c}}$, and Thomas Mueller, MD ${ }^{\mathrm{d}}$
}

Circulating suppression of tumorigenicity 2 (ST2) predicts cardiovascular outcomes and mortality in ischemic heart disease (IHD). ST2 does not correlate with traditional risk indicators as closely as N-terminal pro-brain natriuretic peptide (NT-proBNP) and is only weakly correlated with other biomarkers, indicating distinct pathways for stimulus and release. Although of little diagnostic utility in IHD, ST2 does offer prognostic information. In ST elevation myocardial infarction, ST2 levels increase to peak above the normal reference range (within 6 to 18 hours of symptom onset) in about half of patients. Levels in the upper quartile observed in IHD independently predict cardiovascular death and heart failure with an approximate doubling of risk. Similar but weaker associations have been reported in non-ST elevation myocardial infarction, in which ST2 predicts short-term (30-day) and long-term (>1-year) death and heart failure independent of clinical indicators, but these relations are lost if Global Registry of Acute Coronary Events (GRACE) score and NT-proBNP are added to multivariate models. Early postinfarction levels of ST2 (i.e., $<24$ hours after admission) have the greatest prognostic utility. Early postinfarction ST2 levels and change over 24 weeks are related to infarct extent and remodeling to a similar extent as NT-proBNP and aldosterone, and ST2 may have a significant pathophysiological role in these postinfarction processes. In long-term follow-up of stable IHD, ST2 is predictive of all-cause and cardiovascular mortality independent of accepted clinical indicators and other biomarkers, including NT-proBNP, high-sensitivity C-reactive protein, interleukin-6, high-sensitivitiy cardiac troponin $T$, and galectin-3. In conclusion, ST2 in combination with NT-proBNP consistently improves risk stratification compared with either marker alone. 두 2015 Elsevier Inc. All rights reserved. (Am J Cardiol 2015;115[suppl]:48B-58B)

The suppression of tumorigenicity 2 (ST2) protein was identified $>20$ years ago but remained an orphan receptor until confirmation, in 2005, of interleukin-33 (IL-33) as its endogenous ligand. ${ }^{1}$ In vitro expression of ST2 is upregulated with cardiomyocyte stretch. ${ }^{2}$ In vivo cardiac loading is associated with an increase in circulating levels of ST2. ST2 is present in circulating and membrane-bound forms. In experimental myocardial infarction (MI), IL-33 prevents apoptosis and improves cardiac function and survival. ${ }^{3}$ It has been suggested that circulating "soluble ST2" may act as a "decoy" for IL-33 and in this way reduce access of the interleukin to cardiac membrane-bound receptors, thus

\footnotetext{
${ }^{a}$ Christchurch Heart Institute, University of Otago, Christchurch, New Zealand; ${ }^{\mathrm{b}}$ Cardiovascular Research Institute, National University Heart Centre, Singapore; ${ }^{\mathrm{c}}$ Department of Medical-Surgery Sciences and Translational Medicine, University Sapienza, Emergency Department Sant'Andrea Hospital, Rome, Italy; and ${ }^{\mathrm{d}}$ Department of Laboratory Medicine, Konventhospital Barmherzige Brueder, Linz, Austria.

Publication of this supplement was supported by funding from Critical Diagnostics, San Diego, CA.

Statement of author disclosure: Please see the Author Disclosures section at end of this article.

*Address for reprints: A. Mark Richards, MD, Director, Cardiovascular Research Institute, National University Heart Centre, 1E Kent Ridge Road, NUHS Tower Block, Level 9, (Cardiac Department), NUHCS, Singapore 119228.

E-mail address: mdcarthu@nus.edu.sg.
}

reducing the potential cardioprotective effect of IL-33 in acute and chronic heart disease.

This review summarizes findings with respect to plasma ST2 concentrations and their relations to clinical outcomes across the spectrum of ischemic heart disease (IHD) presentations ranging from populations with undifferentiated chest pain through acute coronary syndromes (ACS) to chronic stable IHD (Table 1).

\section{ST2 in Undifferentiated Chest Pain}

Two reports have addressed the diagnostic and prognostic performance of plasma ST2 concentrations in patients presenting to emergency departments with chest pain., ${ }^{4,5}$

Brown et $\mathrm{al}^{4}$ enrolled 348 patients, aged $\geq 25$ years, presenting to emergency departments with chest pain triggering the acquisition of an electrocardiogram. Blood for ST2 (measured using a research use-only assay) was obtained at presentation, and levels were subsequently assessed for relations to 30-day event rates for acute MI (AMI), ACS, and adverse cardiac events (defined as all-cause mortality, AMI, or revascularization [angioplasty, stent placement, or coronary artery bypass surgery]). Event rates were low at $4.9 \%$ $(\mathrm{n}=17)$ for AMI, $11.2 \%(\mathrm{n}=39)$ for ACS, and $6.6 \%(\mathrm{n}=23)$ for the composite end point. Areas under the receiveroperating characteristic curves (AUCs) for the detection of 
AMI, ACS, and the composite end point were low at 0.636 , 0.630 , and 0.579 , respectively. The investigators concluded that ST2 was not useful in the evaluation of emergency department patients with suspected but not proved ACS.

Aldous et $\mathrm{al}^{5}$ revisited the diagnostic and prognostic utility of ST2 in patients with chest pain in a larger group with longer follow-up and found associations between ST2 and later all-cause mortality and incident heart failure (HF). Nine hundred ninety-five patients reporting ischemic-type pain (including acute chest, gastric, neck, jaw, or arm pain or discomfort or pressure without apparent noncardiac source) were recruited. Blood samples were acquired at 0 and 2 hours after presentation for the measurement of ST2, brain natriuretic peptide (BNP), troponin I (TnI), creatine kinase-MB fraction, and myoglobin. ST2 was weakly correlated with all 4 of the other markers $(\mathrm{R}=0.06$ to 0.30 , $\mathrm{p}=0.044$ to 0.001 , with the strongest correlation with BNP).

The diagnostic performance for the index admission and prognostic performance for events after discharge and up 18 months were assessed for each marker. End points included the composite of all-cause mortality and HF and the individual end points: all-cause mortality, AMI, revascularization, arrhythmia, and stroke. The cut points chosen for each marker were the upper-limit normal values as indicated by the test kit manufacturers. For ST2 this was the 95th percentile of the Critical Diagnostics Presage ST2 assay, $34.3 \mathrm{ng} / \mathrm{ml}$ (limit of detection $1.61 \mathrm{ng} / \mathrm{ml}$, coefficient of variation $10 \%$ at $16.9 \mathrm{ng} / \mathrm{ml}$, and normal range 1.75 to $34.3 \mathrm{ng} / \mathrm{ml}$ ). Patients with ST2 $>34.3 \mathrm{ng} / \mathrm{ml}$ (221 of 995) were more likely to be older; to be female; to have histories of HF, lung disease, diabetes, hypertension, and dyslipidemia; to have lower left ventricular (LV) ejection fractions (LVEFs); to have more frequent regional wall abnormalities; and to have higher plasma creatinine. Events during the index admission included 35 primary end points, 1 death, 34 episodes of HF, and 236 AMIs. ST2 levels were significantly higher in patients with compared with those without these end points.

Relative to the diagnosis of AMI, ST2 clearly underperformed troponin (sensitivity $31.2 \%$, specificity $80.5 \%$ compared with $\mathrm{TnI}$ at $94.5 \%$ and $95.7 \%$, respectively), while for the diagnosis of acute HF, ST2 lacked the sensitivity of BNP (73.5 vs $88.2 \%$ ) but had higher specificity (79.6 vs $66.2 \%$ ).

In contrast to performance for diagnosis, the prognostic performance of ST2 for postdischarge events up to 18-month follow-up was notable. Events from discharge till 18-month included 110 primary (i.e., all-cause death and HF) events (11.1\%), 73 deaths (7.3\%), 52 HF events (5.2\%), 86 AMIs (8.6\%), 57 revascularizations (5.7\%), 49 arrhythmias (4.9\%), and 19 strokes (1.9\%). Survival (Kaplan-Meier) curve analyses indicated a steep increase in risk in those with admission and/or 2-hour ST2 levels above the third quartile $(33.4 \mathrm{ng} / \mathrm{ml})$, a level close to the 95 th percentile $(34.3 \mathrm{ng} / \mathrm{ml})$ used to define the upper limit of normal. Eighteen-month event rates for the primary end point were $4.9 \%, 7.6 \%, 7.2 \%$, and $24.5 \%$ in ST2 quartiles $1,2,3$, and 4 , respectively. Similar results were found for each of death, AMI, HF, arrhythmia, and stroke. Prognostic associations between ST2 and important adverse events remained evident after multivariate analyses that adjusted for age; gender; ethnicity; history of IHD, HF, lung disease, revascularization, stroke, hypertension, and dyslipidemia; smoking status; diabetes; body mass index; the LVEF; regional wall abnormality score; and plasma creatinine. ST2, age, BNP, TnI, myoglobin, the LVEF, and previous IHD were all independently prognostic for the primary outcome.

Elevated ST2 predicted the primary outcome (hazard ratio [HR] 1.9; 95\% confidence interval [CI] 1.2 to 3.2), which was inferior to BNP (HR 2.8; 95\% CI 1.4 to 5.7), equivalent to myoglobin levels, and superior to $\mathrm{TnI}$ and creatine kinase-MB, although for all comparisons, overlap of $95 \%$ CIs existed. In those with initial diagnoses of AMI, ST2 predicted later primary outcome (HR 2.7; 95\% CI 1.2 to 5.7) ST2 also predicted later HF (HR 2.2; 95\% CI 1.0 to $4.7)$ in the population overall. Notably, ST2 was not an independent predictor of later AMI or revascularization.

ST2 combined with BNP improved risk stratification beyond that achieved with either marker alone. Rates for the primary end point over follow-up for those with both markers elevated, BNP alone elevated, ST2 alone elevated, or neither marker raised were $36.8 \%, 19.4 \%, 6.8 \%$, and $2.2 \%$, respectively.

This study was the first to assess the relation of early ST2 levels to later mortality and HF events over prolonged follow-up in a large undifferentiated chest pain population and to compare this prognostic performance with that of other markers. The association of ST2 with death and HF was retained after comprehensive adjustment for other predictors. ST2 and BNP combine to provide better risk stratification than obtained with either alone.

\section{ST2 in ST Elevation Myocardial Infarction}

Two reports on data derived from 3 randomized clinical trials of experimental therapy in ST elevation MI (STEMI) provide data on the predictive power of plasma ST2 for adverse events up to 30 days after MI, and a further article reported on prognostic performance out to a median followup duration of 20 months. ${ }^{6-8}$ ST2 was measured in $>2,000$ patients participating in Thrombolysis In Myocardial Infarction (TIMI) 14, Enoxaparin and Tenecteplase With or Without Glycoprotein IIb/IIIa Inhibitor as Reperfusion Strategy in ST Elevation MI (ENTIRE)-TIMI 23 and Clopidogrel as Adjunctive Reperfusion Therapy (CLARITY)-TIMI 28 trials. ${ }^{6,7}$

Shimpo et $\mathrm{al}^{6}$ measured ST2 in 810 patients with STEMI (362 from TIMI 14 and 448 from ENTIRE-TIMI 23). Patients recruited to these trials had episodes of ischemic discomfort for $\geq 30$ minutes within 6 hours (ENTIRE-TIMI 23) or 12 hours (TIMI 14) and exhibited $\geq 0.1-\mathrm{mV}$ ST-segment elevation in 2 contiguous electrocardiographic 
Table 1

Characterization of outcome studies on stable and unstable ischemic heart disease with sST2 as the target parameter

\begin{tabular}{|c|c|c|c|c|c|c|}
\hline Article & $\begin{array}{l}\text { Study population, } \\
\text { disease group }\end{array}$ & Setting & Primary endpoint & Follow-up & $\begin{array}{c}\text { Number of patients } \\
\text { who reached } \\
\text { endpoint }\end{array}$ & sST2 assay* \\
\hline $\begin{array}{l}\text { Brown AM et al } \\
2007^{4}\end{array}$ & $\begin{array}{l}\mathrm{n}=348 \\
\text { chest pain }\end{array}$ & $\begin{array}{l}\text { emergency department } \\
\text { patients }\end{array}$ & $\begin{array}{l}\text { composite of all-cause } \\
\text { mortality, acute MI, or re- } \\
\text { vascularization }\end{array}$ & $\begin{array}{l}\text { exactly } 30 \text { days for each } \\
\text { study participant }\end{array}$ & $\mathrm{n}=23(7 \%)$ & $\begin{array}{l}\text { MBL assay (commercially } \\
\text { available ready-to-use } \\
\text { assay) }\end{array}$ \\
\hline $\begin{array}{l}\text { Aldous SJ et al } \\
\qquad 2012^{5}\end{array}$ & $\begin{array}{l}\mathrm{n}=995 \\
\text { chest pain }\end{array}$ & $\begin{array}{l}\text { emergency department } \\
\text { patients, post-hoc } \\
\text { analysis of a } \\
\text { prospectively } \\
\text { conducted multicenter } \\
\text { study }\end{array}$ & $\begin{array}{l}\text { composite of all-cause } \\
\text { mortality and heart failure }\end{array}$ & $\begin{array}{l}\text { exactly } 1.5 \text { years for each } \\
\text { study participant }\end{array}$ & $\mathrm{n}=110(11 \%)$ & $\begin{array}{l}\text { Presage assay } \\
\quad \text { (commercially available } \\
\text { ready-to-use assay) }\end{array}$ \\
\hline $\begin{array}{l}\text { Shimpo M et al } \\
2004^{6}\end{array}$ & $\begin{array}{l}\mathrm{n}=810 \\
\text { STEMI }\end{array}$ & $\begin{array}{l}\text { hospitalized patients, } \\
\text { TIMI } 14 \text { and } \\
\text { ENTIRE-TIMI } \\
23 \text { trial } \\
\text { participants }\end{array}$ & all-cause mortality & $\begin{array}{l}\text { exactly } 30 \text { days for each } \\
\text { study participant }\end{array}$ & $\mathrm{n}=28(3 \%)$ & $\begin{array}{l}\text { MBL assay (commercially } \\
\text { available ready-to-use } \\
\text { assay) }\end{array}$ \\
\hline $\begin{array}{l}\text { Sabatine MS } \\
\text { et al } 2008^{7}\end{array}$ & $\begin{array}{l}\mathrm{n}=1239 \\
\mathrm{STEMI}\end{array}$ & $\begin{array}{l}\text { hospitalized patients, } \\
\text { CLARITY-TIMI } 28 \\
\text { substudy }\end{array}$ & $\begin{array}{c}\text { composite of cardiovascular } \\
\text { death and heart failure }\end{array}$ & $\begin{array}{l}\text { exactly } 30 \text { days for each } \\
\text { study participant }\end{array}$ & $\mathrm{n}=87(7 \%)$ & $\begin{array}{l}\text { MBL assay } \\
\text { (commercially } \\
\text { available ready-to-use } \\
\text { assay) }\end{array}$ \\
\hline $\begin{array}{l}\text { Dhillon OS et al } \\
2013^{8}\end{array}$ & $\begin{array}{l}\mathrm{n}=667 \\
\text { STEMI }\end{array}$ & hospitalized patients & all-cause mortality & $\begin{array}{l}\text { exactly } 1.0 \text { year for each } \\
\text { study participant }\end{array}$ & $\mathrm{n}=58(9 \%)$ & $\begin{array}{l}\text { in-house assay } \\
\text { (constructed by the } \\
\text { respective } \\
\text { researchers) }\end{array}$ \\
\hline $\begin{array}{l}\text { Eggers KM et al } \\
2010^{10}\end{array}$ & $\begin{array}{l}\mathrm{n}=403 \\
\text { NSTEMI }\end{array}$ & $\begin{array}{l}\text { hospitalized patients, } \\
\text { GUSTO IV substudy } \\
\text { on inflammatory } \\
\text { markers }\end{array}$ & all-cause mortality & $\begin{array}{l}\text { exactly } 1.0 \text { year for each } \\
\text { study participant }\end{array}$ & $\mathrm{n}=22(6 \%)$ & $\begin{array}{l}\text { Presage assay } \\
\text { (commercially } \\
\text { available ready-to-use } \\
\text { assay) }\end{array}$ \\
\hline $\begin{array}{l}\text { Dhillon OS et al } \\
2011^{11}\end{array}$ & $\begin{array}{l}\mathrm{n}=577 \\
\mathrm{NSTEMI}\end{array}$ & hospitalized patients & $\begin{array}{l}\text { composite of all-cause } \\
\text { mortality, heart } \\
\text { failure hospitalization, and } \\
\text { re-infarction }\end{array}$ & mean of approx. 1.5 years & $\mathrm{n}=156(27 \%)$ & $\begin{array}{l}\text { in-house assay (constructed } \\
\text { by the respective } \\
\text { researchers) }\end{array}$ \\
\hline $\begin{array}{l}\text { Kohli P et al } \\
2012^{12}\end{array}$ & $\begin{array}{l}\mathrm{n}=4426 \\
\text { NSTEMI }\end{array}$ & $\begin{array}{l}\text { hospitalized patients, } \\
\text { substudy of the } \\
\text { MERLIN-TIMI } 36 \\
\text { trial }\end{array}$ & $\begin{array}{l}\text { composite of cardiovascular } \\
\text { mortality and new or } \\
\text { worsening heart failure }\end{array}$ & mean of approx. 1.0 year & not provided & $\begin{array}{l}\text { Presage assay } \\
\quad \text { (commercially available } \\
\text { ready-to-use assay) }\end{array}$ \\
\hline $\begin{array}{l}\text { Demyanets S } \\
\quad \text { et al } 2014^{13}\end{array}$ & $\begin{array}{l}\mathrm{n}=373 \\
\text { STEMI, } \\
\text { NSTEMI, } \\
\text { and stable } \\
\text { angina }\end{array}$ & hospitalized patients & all-cause mortality & mean of approx. 3.5 years & $\mathrm{n}=37(10 \%)$ & $\begin{array}{l}\text { R\&D assay (commercially } \\
\text { available ready-to-use } \\
\text { assay) }\end{array}$ \\
\hline $\begin{array}{l}\text { Dieplinger B } \\
\text { et al } 2014^{15}\end{array}$ & $\begin{array}{l}\mathrm{n}=1345 \\
\text { stable coronary } \\
\text { artery disease }\end{array}$ & $\begin{array}{l}\text { hospitalized patients, } \\
\text { substudy of the } \\
\text { LURIC study }\end{array}$ & all-cause mortality & median of approx. 9.8 years & $\mathrm{n}=477(36 \%)$ & $\begin{array}{l}\text { Presage assay } \\
\text { (commercially } \\
\text { available ready-to-use } \\
\text { assay) }\end{array}$ \\
\hline $\begin{array}{l}\text { Weir RA et al } \\
2010^{16}\end{array}$ & $\begin{array}{l}\mathrm{n}=100 \\
\text { acute } \mathrm{MI}\end{array}$ & hospitalized patients & $\begin{array}{l}\text { left ventricular functional } \\
\text { recovery after acute MI }\end{array}$ & $\begin{array}{l}\text { exactly } 24 \text { weeks for each } \\
\text { study participant }\end{array}$ & not applicable & $\begin{array}{l}\text { R\&D assay } \\
\text { (commercially } \\
\text { available ready-to-use } \\
\text { assay) }\end{array}$ \\
\hline
\end{tabular}

BNP, B-type natriuretic peptide; CI, confidence interval; CRP, C-reactive protein; cTnI, cardiac troponin I; cTnT, cardiac troponin T; GRACE score, Global Registry of Acute Coronary Events risk score; HR, hazard ratio; IL-6, interleukin-6; IL-33, interleukin-33; LVEF, left ventricular ejection fraction; MI, myocardial infarction; n.a., not applicable; NSTEMI, non-ST-segment elevation acute coronary syndrome, NT-proBNP, N-terminal pro B-type natriuretic peptide; STEMI, ST-segment elevation myocardial infarction.

*Results obtained with different sST2 assays are not comparable; the assays are not standardized. One should be aware with which method the results were produced. Commercially available assays: Presage assay (Presage ST2 kit, Critical Diagnostics, San Diego, CA, USA), the MBL ST2 assay (Human ST2 ELISA kit, Medical\&Biological Laboratories, Woburn, MA, USA), and the R\&D ST2 assay (ST2/IL-1 R4 DuoSet ELISA or Quantikine ELISA, R\&D Systems, Minneapolis, MN, USA).

leads. Blood for ST2 measurements was taken at presentation. Using an older generation research use-only ST2 assay (Medical and Biological Laboratories Co., Ltd.) the authors found levels higher $(0.379$ vs $0.233 \mathrm{ng} / \mathrm{ml}$, $\mathrm{p}<0.001)$ in those who died or developed HF over 30 days after STEMI. Ascending quartiles of plasma ST2 significantly corresponded to increasing time from symptom onset, higher heart rates, higher cardiac TnI, higher BNP, higher $\mathrm{C}$-reactive protein (CRP), higher creatinine, and increasing likelihood of an anterior location of the MI. Notably most of the elevation in these covariates occurred between the third and fourth quartiles of plasma ST2. In this STEMI population, ST2 was correlated weakly with $\mathrm{TnI}(\mathrm{r}=0.26$, $\mathrm{p}<0.0001)$ but not with BNP. Over 30 days, events 
Table 1

(continued)

\begin{tabular}{|c|c|c|c|c|c|}
\hline $\begin{array}{l}\text { Utilization of sST2 as } \\
\text { predictor variable }\end{array}$ & $\begin{array}{l}\mathrm{HR}(95 \% \mathrm{CI}) \text { in } \\
\text { univariate } \\
\text { Cox-regression }\end{array}$ & $\begin{array}{l}\mathrm{HR}(95 \% \mathrm{CI}) \text { in } \\
\text { multivariate } \\
\text { Cox-regression }\end{array}$ & $\begin{array}{l}\text { Other independent variables in } \\
\text { multivariate } \\
\text { Cox-regression }\end{array}$ & $\begin{array}{l}\text { Cut-point reported for } \\
\text { sST2* }\end{array}$ & Additional information \\
\hline continuous & not applied & not applied & not applied & no cut-point provided & $\begin{array}{l}\text { area under the curve for prediction } \\
\text { of outcome, } 0.58 \text { ( } 95 \% \mathrm{CI}, 0.48 \text { - } \\
0.68 \text { ) }\end{array}$ \\
\hline $\begin{array}{l}\text { dichotomous, }>34 \mathrm{ng} / \\
\quad \mathrm{mL}\end{array}$ & not provided & $1.9(1.2-3.2)$ & $\begin{array}{l}\text { a variety of clinical variables and } \\
\text { several biomarkers including BNP } \\
\text { and cTnI }\end{array}$ & $\begin{array}{l}34 \mathrm{ng} / \mathrm{mL} \text {, cut-point by } \\
95^{\text {th }} \text { percentile }\end{array}$ & $\begin{array}{l}\text { sST2, cTnI and BNP provided } \\
\text { independent prognostic } \\
\text { information }\end{array}$ \\
\hline
\end{tabular}

incremental, per $1 \mathrm{ng} /$ not provided $\mathrm{mL}$ rise
$1.8(1.0-3.1)$ clinical variables only (age, heart rate, $0.235 \mathrm{ng} / \mathrm{mL}$, cut-point sST2 lost its independent prognostic systolic blood pressure, location of by median value when BNP and cTnI were MI, Killip class, and time from onset of chest pain) entered into multivariate analysis

\begin{tabular}{|c|c|c|c|c|c|}
\hline $\begin{array}{l}\text { incremental, } \log _{10^{-}} \\
\text {transformed } \\
\text { concentrations per } 1 \\
\text { unit }\end{array}$ & $\begin{array}{l}2.4(1.7-3.5) \text { (cave: this is } \\
\text { an odds ratio because } \\
\text { logistic regression was } \\
\text { applied) }\end{array}$ & $\begin{array}{l}1.9(1.3-3.0) \text { (cave: this is } \\
\text { an odds ratio because } \\
\text { logistic regression was } \\
\text { applied) }\end{array}$ & $\begin{array}{l}\text { clinical variables only (including } \\
\text { infarct location, Killip class, time to } \\
\text { initiation of fibrinolytic therapy, } \\
\text { and type of lytic) }\end{array}$ & $\begin{array}{l}0.080 \mathrm{ng} / \mathrm{mL} \text {, cut-point } \\
\text { by median }\end{array}$ & $\begin{array}{l}\text { SST2 and NT-proBNP provided } \\
\text { independent and additive } \\
\text { prognostic information }\end{array}$ \\
\hline $\begin{array}{l}\text { incremental, } \log _{10^{-}} \\
\text {transformed } \\
\text { concentrations per } 1 \\
\text { unit }\end{array}$ & $9.1(5.2-16.0)$ & $2.6(1.2-5.4)$ & $\begin{array}{l}\text { a variety of clinical variables including } \\
\text { GRACE score and several } \\
\text { biomarkers including NT-proBNP } \\
\text { (but not cTnI or cTnT) }\end{array}$ & $\begin{array}{l}0.862 \mathrm{ng} / \mathrm{mL} \text {, cut-point } \\
\text { set arbitrarily } \\
\text { for } 30 \text {-day mortality }\end{array}$ & $\begin{array}{l}\text { SST2 and IL-33 were } \\
\text { simultaneously evaluated as } \\
\text { outcome predictors }\end{array}$ \\
\hline $\begin{array}{l}\text { incremental, } \log _{e^{-}} \\
\text {transformed } \\
\text { concentrations per } 1 \\
\text { standard deviation }\end{array}$ & not provided & $\begin{array}{l}2.3(1.1-4.6) \text { (cave: this is } \\
\text { an odds ratio because } \\
\text { logistic regression was } \\
\text { applied) }\end{array}$ & $\begin{array}{l}\text { age, heart failure, diabetes mellitus, } \\
\text { previous MI or stroke, but no } \\
\text { biomarkers (such as NT-proBNP, } \\
\text { cTnT or CPR) }\end{array}$ & no cut-point provided & $\begin{array}{l}\text { serial measurement of sST2: } \mathrm{sST} 2 \\
\text { concentrations decreased in time } \\
\text { course from baseline to } 72 \text { hours } \\
\text { thereafter }\end{array}$ \\
\hline $\begin{array}{l}\text { incremental, } \log _{10^{-}} \\
\text {transformed } \\
\text { concentrations per } 1 \\
\text { unit }\end{array}$ & $3.6(2.3-5.6)$ & $2.0(1.2-3.3)$ & $\begin{array}{l}\text { a variety of clinical variables and } \\
\text { several biomarkers including cTnI }\end{array}$ & no cut-point provided & $\begin{array}{l}\text { SST2 lost its independent prognostic } \\
\text { value when GRACE score and NT- } \\
\text { proBNP were entered into } \\
\text { multivariate analysis }\end{array}$ \\
\hline $\begin{array}{l}\text { incremental, } \log _{10^{-}} \\
\text {transformed } \\
\text { concentrations per } 1 \\
\text { unit }\end{array}$ & $1.6(1.4-1.7)$ & $1.3(1.1-1.4)$ & $\begin{array}{l}\text { a variety of clinical variables and } \\
\text { several biomarkers including BNP } \\
\text { and cTnI }\end{array}$ & $\begin{array}{l}35 \mathrm{ng} / \mathrm{mL} \text {, cut-point by } \\
\text { highest quartile }\end{array}$ & $\begin{array}{l}\text { sST2, cTnI and BNP provided } \\
\text { independent and additive } \\
\text { prognostic information }\end{array}$ \\
\hline $\begin{array}{l}\text { dichotomous, }>0.538 \\
\mathrm{ng} / \mathrm{mL}\end{array}$ & $2.1(1.1-4.2)$ & $2.2(1.1-4.4)$ & $\begin{array}{l}\text { age, gender, hyper-lipidemia, hyper- } \\
\text { tension, smoking, creatinine but no } \\
\text { biomarkers (such as NT-proBNP, } \\
\text { cTnT or CPR) }\end{array}$ & $\begin{array}{c}0.538 \mathrm{ng} / \mathrm{mL} \text {, cut-point } \\
\text { by highest quintile }\end{array}$ & $\begin{array}{l}\text { SST2 and IL-33 were } \\
\text { simultaneously evaluated as } \\
\text { outcome predictors }\end{array}$ \\
\hline $\begin{array}{l}\text { incremental, } \log _{10^{-}} \\
\text {transformed } \\
\text { concentrations per } 1 \\
\text { standard deviation }\end{array}$ & $1.5(1.3-1.6)$ & $1.2(1.0-1.3)$ & $\begin{array}{l}\text { a variety of clinical variables and } \\
\text { several biomarkers including cTnT, } \\
\text { NT-proBNP, CRP, IL-6, and } \\
\text { galectin-3 }\end{array}$ & $\begin{array}{l}25 \mathrm{ng} / \mathrm{mL} \text {, cut-point by } \\
\text { highest quartile }\end{array}$ & $\begin{array}{l}\text { sST2, cTnT and NT-proBNP } \\
\text { provided independent and } \\
\text { additive prognostic information }\end{array}$ \\
\hline $\begin{array}{l}\text { SST2 was correlated } \\
\text { with baseline and 24- } \\
\text { week measurements } \\
\text { of LV function }\end{array}$ & not applied & not applied & not applied & no cut-point provided & $\begin{array}{l}\text { baseline sST2 was associated with } \\
\text { baseline and } 24 \text {-week LVEF and } \\
\text { with baseline and } 24 \text {-week infarct } \\
\text { volume index }\end{array}$ \\
\hline
\end{tabular}

included 28 deaths, 29 recurrent MIs, $21 \mathrm{HF}$ events, and 47 death and HF composite events. ST2 levels were higher in subsequent decedents than in survivors and also in those incurring HF but not in those with recurrent MI. This pattern reinforces the repeated finding that ST2 predicts death and HF but not recurrent ischemic events. Despite these relatively small numbers of events, risk for inpatient death increased with quartile of ST2 $(0.98 \%, 1.5 \%, 3.0 \%$, and $6.4 \%$ in quartiles $1,2,3$, and 4 , respectively; $p=0.0008$ ), whereas corresponding percentages for in-hospital recurrent MI $(4.4 \%, 3.5 \%, 0.5 \%$, and $1.5 \%$, respectively) showed no pattern of association with increasing ST2. Thirty-day event rates also revealed the key ST2-associated end points to be death and HF. Notably, those with inframedian levels of 
ST2 on admission incurred no further death or HF in the interval between discharge and 30-day follow-up. Again, there was no association with increased risk for recurrent MI at 30 days, with an almost inverse trend between quartile of ST2 and risk for new MI $(5.4 \%, 4.5 \%, 2.5 \%$, and $2.0 \%$ in ST2 quartiles 1, 2, 3, and 4, respectively).

In multivariate analysis ST2 remained predictive of mortality at 30 days, after controlling for age, heart rate, blood pressure, location of infarction, Killip class, and time from symptom onset (HR per $1 \mathrm{ng} / \mathrm{ml}$ increase 1.77 ; $95 \%$ CI 1.01 to $3.12, \mathrm{p}=0.047$ ), but the independent association was lost once BNP and TnI were added to the model (this was possible only for $\mathrm{n}=448$ in the ENTIRE-TIMI 23 subpopulation). In the TIMI 14 subcohort, additional samples were taken at later time points, and ST2 at 12 hours from presentation remained independently predictive of mortality after adjustment for age, heart rate, blood pressure, location of MI, Killip class, and time from symptom onset ( $\mathrm{p}$ $<0.01)$. The investigators concluded that ST2 is associated with mortality after STEMI independent of established clinical indicators. They did not provide any assessment of the risk stratification potentially offered by marker combinations such as ST2 coupled with either TnI or BNP.

These findings were reinforced and extended by data from the CLARITY-TIMI 28 trial in STEMI, which also provided a compelling analysis of the complementarity of ST2 and the established marker N-terminal pro-BNP (NT-proBNP). ${ }^{7}$ ST2 was measured on recruitment to the trial in 1,239 patients. Ascending quartiles of plasma ST2 were associated with diabetes, creatinine clearance (although the difference in estimated glomerular filtration rate (eGFR) between ST2 quartiles 1 to 4 was $<6 \mathrm{ml} / \mathrm{min}$ ) but not related to other clinical characteristics often considered to associate with chronic LV wall stress, including age, hypertension, previous MI, or previous HF. The correlation with NT-proBNP was weak $(r=$ $0.14, \mathrm{p}<0.001)$. NT-proBNP was correlated with age, gender, hypertension, previous $\mathrm{MI}$, previous $\mathrm{HF}$, and lower creatinine clearance (quartile 1 to quartile $4 \mathrm{ST} 2$ interquartile difference in eGFR about $16 \mathrm{ml} / \mathrm{min}$ ). This striking nonparallelism of the relations of the 2 markers with common covariates supports the concept of different primary drivers for their production and secretion.

The temporal patterns of change in plasma ST2 and NT-proBNP in the post-MI period also differ. Repeat sampling in most patients was undertaken at angiography a mean of about 4 days after MI. ST2 decreased modestly an average of $0.009 \mathrm{ng} / \mathrm{ml}$, while mean NT-proBNP increased nearly sixfold by an average of $386 \mathrm{pg} / \mathrm{ml}$ ( $\mathrm{p}<0.001$ for the 2 changes from baseline). Notably, plasma ST2 differed between patients with and without angiographic TIMI flow grade 0 and between those with and without TIMI myocardial perfusion grade 0 (both adverse appearances were associated with about threefold higher ST2 levels) than was the case for NT-proBNP (about $40 \%$ differences), whereas the natriuretic peptide marker was clearly more closely associated with LVEF than ST2 ( $\mathrm{r}=-0.45$ vs $r=-0.17)$. These findings suggest plasma ST2 reflects the quantum of injured tissue and associated necrosis and inflammatory events, whereas the primary driver for NT-proBNP remains cardiac mechanical stress.

For ST2 and NT-proBNP, the mean plasma concentrations observed in those later incurring cardiovascular (CV) death or HF were four- to fivefold those in patients spared these outcomes. In patients later experiencing strokes, marker levels were two- to four-fold those in patients spared stroke. In contrast, ST2 levels were almost identical $(0.074$ vs $0.079 \mathrm{ng} / \mathrm{ml}$ ) in those with and without later recurrent MI. Although NT-proBNP levels did differ for this end point (108 vs $70 \mathrm{pg} / \mathrm{ml}, \mathrm{p}=0.0013$ ), it was to a far lesser degree than for death or HF. Thirty-day CV death rates by quartile of ST2 were $2.5 \%, 3.2 \%, 3.2 \%$, and $9 \%$ in quartiles $1,2,3$, and 4 , respectively, with corresponding percentages of $1.4 \%, 1.0 \%, 5.1 \%$, and $10.5 \%$ for successive quartiles of NT-proBNP. Similar patterns were observed for incident $\mathrm{HF}$. The most pronounced increase in risk occurred from the third to the fourth quartile of ST2 values, whereas the increasing risk associated with increasing NT-proBNP was more smoothly graded across successive quartiles. Notably, ST2 levels at baseline were superior to levels 4 days later (i.e., at angiography) for the prediction of death or $\mathrm{HF}$, whereas the opposite was true of NT-proBNP. If corroborated, this observation will inform optimal peri-infarct timing of sampling, which, for prognostic applications, may differ for these 2 markers.

In multivariate analysis with adjustment for age, gender, hypertension, diabetes, previous MI, previous HF, creatinine clearance, infarct location, Killip class, time from symptom onset to lytic therapy, and peak creatine kinase, a 1-SD elevation in log-transformed ST2 was associated with a 1.94-fold (95\% CI 1.25-fold to 3.03-fold) increase in risk for $\mathrm{CV}$ death or $\mathrm{HF}$ over 30 days $(\mathrm{p}=0.003)$. The analogous result for NT-proBNP was 1.46-fold $(95 \%$ CI 1.22-fold to 1.76-fold, $\mathrm{p}<0.001$ ). In a multimarker model including ST2 and NT-proBNP plus all the traditional predictors, the 2 markers remained independent predictors of $\mathrm{CV}$ death or $\mathrm{HF}$, with odds ratios per 1-SD elevation in log levels of 1.88 (95\% CI 1.17 to 3.03, $\mathrm{p}=0.009)$ and $1.41(95 \% \mathrm{CI} 1.17$ to $1.69, \mathrm{p}<0.001)$ for ST2 and NT-proBNP, respectively. Figure 1 illustrates combined risk stratification using TIMI risk score together with ST2 and NT-proBNP.

Risk for CV death or HF at 30 days increased from about $0.6 \%$ when neither marker was elevated above the median value for the group and the TIMI risk score was 0 or 1 to about $26 \%$ when the 2 markers were above the median values and the TIMI risk score was $\geq 4$ (Figure 1). When the 2 markers were included in the model, the $c$-statistic for prediction of death or HF increased from 0.82 to 0.86 . In summary, this study demonstrated ST2 to be a strong predictor of $\mathrm{CV}$ death within 30 days after STEMI independent of traditional risk factors and complementary to NT-proBNP. 


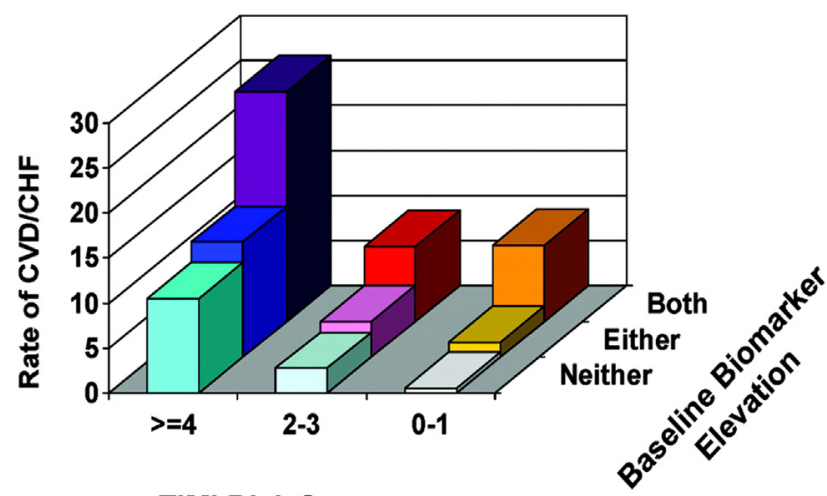

TIMI Risk Score

Figure 1. Combined risk stratification with the TIMI risk score for STEMI and NT-proBNP and ST2. Rate of CV death or HF in patients was categorized into 9 groups on the basis of the TIMI risk score for STEMI and biomarker status; the latter was categorized as neither ST2 and NT-proBNP higher than the median, 1 of the 2 higher than the median, or both higher than the median. The numbers of patients with events and patients in each group are as follows (from left to right and from back to front): 36 of 141, 10 of 121,5 of 59,16 of 125, 9 of 226,3 of 181,4 of 38, 3 of 109, and 1 of $167 .^{7}$

Dhillon et $\mathrm{al}^{8}$ measured ST2 and its endogenous ligand, IL-33, in a study of patients with STEMI that extended the window of observation beyond 30 days out to a median follow-up duration of about 20 months. ST2 and IL-33 were measured in samples acquired 3 to 5 days after admission in 677 patients with STEMI. Median follow-up duration was 587 days (interquartile range [IQR] 134 to 2,818), during which 101 patients $(15 \%)$ died.

ST2 was correlated with NT-proBNP $(r=0.32)$, Global Registry of Acute Coronary Events (GRACE) risk score $(r=0.22)$, age $(r=0.20)$, and peak creatinine phosphokinase $(r=0.16)$ and negatively with eGFR $(r=-0.22)$, all significant at $\mathrm{p}<0.001$. As in previous studies, supramedian levels of ST2 $(>0.677 \mathrm{ng} / \mathrm{ml})$ were associated with greater age, a higher rate of diabetes, lower eGFR, a lower ejection faction, a higher GRACE score, and higher NT-proBNP level. They also tracked with lower rates of prescription of indicated drugs (angiotensin-converting enzyme inhibitors or angiotensin II receptor blockers, $\beta$ blockers, aspirin, and statins) at discharge.

Importantly, supramedian ST2 was associated with threefold greater rates of death and HF. Levels in subsequent decedents were significantly higher than in survivors (median $1.125 \mathrm{ng} / \mathrm{ml}$ [range 0.123 to 15.781 ] vs $0.630 \mathrm{ng} / \mathrm{ml}$ [range 0.590 to 11.729 ], $\mathrm{p}<0.001$ ), as were IL-33 levels (median $75 \mathrm{pg} / \mathrm{ml}$ [range 5.4 to 17,983 ] vs $5.4 \mathrm{pg} / \mathrm{ml}$ [range 5.4 to $16,466], \mathrm{p}=0.006$ ). For multivariate analysis, a Cox regression model was constructed including age, gender, history of angina or AMI, hypertension, diabetes, Killip class, eGFR, peak creatine kinase level, and treatment with thrombolysis, $\beta$ blockers, statins, angiotensin-converting enzyme inhibitors, or angiotensin II receptor blockers. ST2 was associated with increased risk for death within 30 days (HR 9.34, $\mathrm{p}<0.001$ ) and at 1 year (HR 3.15, $\mathrm{p}=0.001)$. The predictive power of ST2 was retained after further adjustment for GRACE risk score as calculated on admission ${ }^{9}$ and NT-proBNP. The $c$-statistic for prediction of death by 30 days improved from 0.82 to 0.84 for any 1 of the 3 predictors alone to $0.90(\mathrm{p}=0.01)$ when ST2, GRACE risk score, and NT-proBNP were combined. IL-33 $>5.4 \mathrm{pg} / \mathrm{ml}$ was independently predictive of 30-day and 1-year mortality but did not add prognostic information over that provided by GRACE risk score or NT-proBNP. Those readmitted with HF had higher ST2 $(1.081 \mathrm{ng} / \mathrm{ml}, \mathrm{p}<0.001)$ compared with the eventfree group. On univariate analysis, ST2 was associated with $\mathrm{HF}$ readmission at 30 days and 1 year, but this did not retain statistical significance after multivariate adjustment. This discrepancy with earlier studies is not readily explained, but it may reflect the timing of sampling. In Sabatine et al, admission values of ST2 were notably better at prediction of $\mathrm{CV}$ death or $\mathrm{HF}$ than were levels at 4 days after admission. Dhillon et $\mathrm{al}^{8}$ collected samples at 3 to 5 days and may therefore have lost some of the prognostic power of plasma ST2 for this end point. For those who experienced reinfarction, ST2 levels were similar to those in the event-free group $(0.649 \mathrm{ng} / \mathrm{ml}, \mathrm{p}=0.89)$. Consistent with earlier reports, on univariate analysis and after multivariate adjustment, higher ST2 predicted lower recurrent MI (HR 0.13, $\mathrm{p}=0.004)$.

Notably, IL-33 levels were lower than the limit of detection in half of patients, possibly obscuring the true relation between IL-33 and outcomes. Development of more sensitive assays may allow this question to be revisited at a later time.

This report consolidates consistent findings in STEMI with respect to the prognostic utility of ST2 in the early (30day) post-MI period and also indicates that the prognostic signal (for death) offered by ST2 levels extends beyond 30 days to $\geq 1$ year. ST2 adds to information from traditional risk indicators (including those integrated in the admission GRACE score) and from NT-proBNP. The inverse relation with risk for recurrent $\mathrm{MI}$ has now been observed in all 3 reports of STEMI series, although its mechanism remains obscure. It is possible that patients with high peri-infarct ST2 have incurred more "complete" infarcts, whereas lower ST2 levels in STEMI may signify "unfinished business," with high-risk coronary plaque and anatomy remaining in situ to pose a continued risk for reinfarction.

\section{ST2 in Non-ST Elevation Acute Coronary Syndromes}

The performance of ST2 in non-STEMI (NSTEMI) and non-ST elevation ACS overall has been explored in at least 4 reports since $2010 .^{10-13}$

Eggers et $\mathrm{al}^{10}$ studied serial ST2 levels measured using the Critical Diagnostics Presage ST2 assay in 403 of 7,800 patients recruited into the Global Use of Strategies to Open Occluded Arteries (GUSTO) IV study. Patients were eligible for inclusion in GUSTO IV (a randomized trial of 
adjunctive treatment of NSTEMI with abciximab with neutral results) if they had ischemic symptoms lasting $\geq 5$ minutes $<24$ hours before admission together with either a positive cardiac troponin test result (above the upper limit of normal for the local assay) or $\geq 0.5$-mm ST-segment depression. Blood samples were acquired at randomization and at 24, 48, and 72 hours after randomization. Other biomarkers, measured at randomization only, included troponin T, NT-proBNP, CRP, and interleukin-6 (IL-6). Peak ST2 levels were observed at 6 to 17 hours after symptom onset, consistent with data previously reported in STEMI patients. ${ }^{6}$ Levels subsequently decreased to a stable level of about $20 \mathrm{ng} / \mathrm{ml}$ by 24 to 42 hours after symptom onset. ST2 levels higher than the respective gender-specific upper reference levels were noted in 219 patients $(44.8 \%)$ at randomization, 140 patients $(29.1 \%)$ at 24 hours, 104 patients $(25.8 \%)$ at 48 hours, and 103 patients $(25.6 \%)$ at 72 hours. Therefore, $<1 / 2$ of patients with NSTEMI have ST2 levels above the normal range at presentation.

Supramedian admission ST2 levels (i.e., $>28.4 \mathrm{ng} / \mathrm{ml}$ ) were associated with a higher percentage of men and more hypertension but, in contrast to several earlier reports, no greater prevalence of diabetes or renal dysfunction. Supramedian ST2 also associated with significantly higher levels of NT-proBNP, CRP, troponin, and CRP. There were significant $(\mathrm{p}<0.01)$ albeit weak associations between ST2 and cardiac troponin $\mathrm{T}(\mathrm{cTnT})(\mathrm{r}=0.27)$, NT-proBNP $(\mathrm{r}=$ $0.25)$, CRP $(r=0.15)$, and IL-6 $(r=0.20)$ but not between ST2 and eGFR $(r=-0.06, p=0.21)$.

Twenty-two patients (5.5\%) died in the following year. Randomization ST2 levels were higher in subsequent decedents. Notably, this distinction was most clear cut at randomization, and ST2 levels did not differ between groups beyond 24 hours. This again emphasizes the importance of early ST2 levels for the best prognostic information, a pattern quite different from that of NT-proBNP. The AUC of randomization ST2 levels for 1-year mortality was 0.67 . Corresponding and comparable AUCs for the other markers were cTnT 0.64, CRP 0.69, IL-6 0.68, and eGFR 0.72. Notably, NT-proBNP significantly $(\mathrm{p}=0.03)$ outperformed ST2 and the other markers, with an AUC of 0.78. The $c$-statistics for ST2 decreased progressively over serial measurements down to 0.60 at 72 hours, implying the importance of early ST2 measurement in the setting of ACS.

Multivariate analysis included clinical variables related to 1-year mortality (age, HF, diabetes mellitus, previous MI, and previous stroke). A 1-SD increase in log-transformed ST2 was associated with an approximate twofold increased risk (odds ratio $2.3,95 \%$ CI 1.1 to $4.6, \mathrm{p}=0.03$ ). However, adding other biomarkers to the model (cTnT, NTproBNP, CRP, IL-6, fibrinogen, and eGFR) removed the independent prognostic value of initial ST2 levels. A 1-SD increase in log NT-proBNP was the strongest risk predictor (odds ratio $1.9,95 \%$ CI 1.3 to $2.8, \mathrm{p}=0.002$ ). The shift in ST2 levels from randomization to 72 hours was not predictive for 1-year mortality. Differences in sampling times or the larger amount of affected myocardium in STEMI compared with non-ST-segment elevation ACS may both be relevant. ST2 might be more useful for prognosis in patients with larger MIs.

Dhillon et $\mathrm{al}^{11}$ examined both ST2 and IL-33 in NSTEMI according to the same design as in their report on patients with STEMI. Samples were acquired from 577 patients 3 to 5 days after admission. The primary end point was a composite of major adverse cardiac events (MACEs; combined mortality, HF admission, and reinfarction), with the individual MACE components also analyzed as separate secondary end points. Increasing quartiles of ST2 were associated with an increasing proportion of diabetes, increased Killip class, and previous MI. ST2 was correlated positively with NT-proBNP, GRACE risk score, glucose, and age and negatively with eGFR ( $p<0.001$ for all) but was not related to troponin. Over an average follow-up period of 532 days (range 150 to 1,059), 156 patients $(27 \%)$ had MACEs. ST2 was higher in these patients than in event-free survivors (median 0.782 vs $0.596 \mathrm{ng} / \mathrm{ml}$, $\mathrm{p}<0.001)$. IL-33 levels did not differ for any end point. By survival-curve analysis, mortality increased with increasing quartile of ST2, but notably, separation by quartiles of GRACE score for MACEs and death gave wider risk stratification (with sharper separation of very high from very low risk patients) than did ST2.

On multivariate analysis (with adjustment for age, gender, previous angina or AMI, HF, hypertension, diabetes, Killip class, eGFR, glucose, $\beta$ blockers or statins, TnI, dyslipidemia, and smoking), a 10-fold increase in ST2 was independently associated with increased risk for MACEs (HR 2.01, p = 0.005), death, and MI during the long term. ST2 also independently predicted 30-day mortality ( $\mathrm{HR} 4.43, \mathrm{p}=0.02$, $c$-statistic $0.73, \mathrm{p}<0.001$ ) and reinfarction (HR 2.48, p = $0.03)$. ST2 predicted HF in the short and long terms on univariate analysis, but this relation was not seen in any multivariate model. The relation to long-term events remained on further adjustment for GRACE risk score or for NT-proBNP but not when the 2 were added to the model. Accordingly, adding ST2 to GRACE risk score or to NT-proBNP did not lead to improvements in the $c$-statistic for MACEs for longterm follow-up or to significant net reclassification improvement. Neither IL-33 nor its ratio with ST2 was prognostic.

The predictive signal from elevated ST2 for reinfarction in this study is in jarring contrast to data from multiple studies in patients with STEMI in which ST2 exhibited an inverse relation to risk for further infarction. ${ }^{6-8}$ This discrepancy is not readily explained.

The largest study of ST2 in non-ST elevation ACS reported to date is from the Metabolic Efficiency With Ranolazine for Less Ischemia in the Non-ST-Elevation Acute Coronary Syndrome-TIMI 36 (MERLIN-TIMI 36) study, a placebo-controlled trial of ranolazine in non-STsegment elevation ACS. ${ }^{12}$

Enrollees had some high-risk features, including increased biomarkers, ST depression $>0.1 \mathrm{mV}$, diabetes, or 


\section{A}
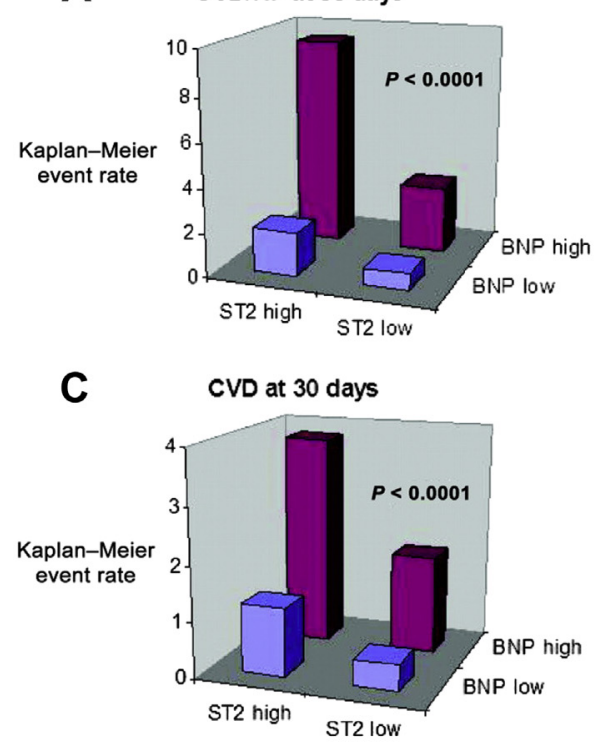
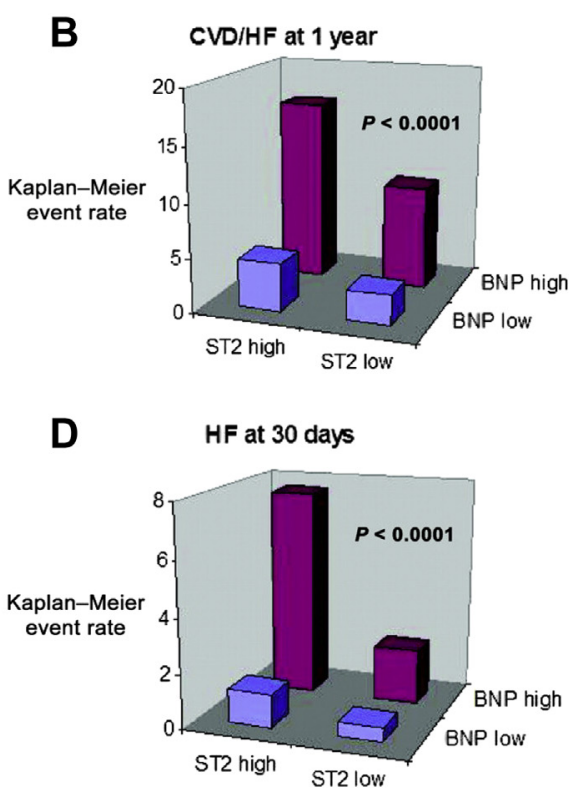

Figure 2. Kaplan-Meier event rates for $\mathrm{CV}$ death or $\mathrm{HF}(A, B)$ and $\mathrm{CVD}(C)$ and $\mathrm{HF}(D)$ alone are highest in patients with high ST2 and high BNP. ${ }^{12}$

an intermediate to high $(>3)$ TIMI score. ST2 was assayed in baseline samples from 4,426 of the 6,560 MERLIN-TIMI 36 participants using the Presage ST2 method.

Median plasma ST2 was $24.4 \mathrm{ng} / \mathrm{ml}$ (IQR 17.6 to 35.1, range 0.35 to 784.35 ). ST2 concentrations in the top quartile $(>35 \mathrm{ng} / \mathrm{ml}$ ) were associated with greater age, a higher percentage of men, diabetes, and renal dysfunction but not with any difference in the prevalence of antecedent MI or HF. ST2 was weakly correlated with troponin and BNP. High ST2 was associated with increased risk for $\mathrm{CV}$ death or $\mathrm{HF}$ at 30 days $(6.6 \%$ vs $1.6 \%, \mathrm{p}<0.0001)$ and 1 year $(12.2 \%$ vs $5.2 \%, \mathrm{p}$ $<0.0001)$. The risk associated with ST2 was significant after adjustment for clinical covariates and biomarkers (including age, coronary artery disease [CAD], diabetes, hypertension, dyslipidemia, severe angina [ $>2$ episodes in 24 hours], ST changes $>0.5 \mathrm{~mm}$, aspirin, smoking, history of HF, eGFR $<60 \mathrm{ml} / \mathrm{min}$, and other biomarkers, including cTnI, BNP, myeloperoxidase, and high-sensitivity CRP). The LVEF was added to the model when available.

The HR for CV death or HF at 30 days for ST2 $>35$ versus $<35 \mathrm{ng} / \mathrm{ml}$ was $1.90(95 \%$ CI 1.15 to $3.13, \mathrm{p}=$ $0.012)$ and at 1 year was 1.51 (95\% CI 1.15 to $1.98, \mathrm{p}$ $<0.003$ ), with significant integrated discrimination improvement $(\mathrm{p}<0.0001)$ but no significant change in $c$-statistic or net reclassification. Similar significant increased risks (i.e., 1.5- to 2-fold) were also observed in high-ST2 patients (i.e., $>35 \mathrm{ng} / \mathrm{ml}$ ) after completely adjusted analyses for the 3 individual end points (i.e., allcause mortality, CV death, and HF). Unlike BNP, ST2 was not associated with the composite of CV death, MI, or recurrent ischemia (HR 1.13, 95\% CI 0.98 to $1.30, \mathrm{p}=$ $0.10)$. This report did not include information on associations of ST2 with risk for reinfarction alone.

Again, combining ST2 with BNP improved risk stratification. Event rates incurred by those with elevation of the
2 markers were three- to fourfold those seen with low values of the 2 markers (Figure 2).

Hence, in this very large (and therefore well-powered) sample of moderate- to high-risk patients with non-ST elevation ACS, plasma ST2 proved predictive of death, CV death, $\mathrm{HF}$, and the composite of $\mathrm{CV}$ death and $\mathrm{HF}$ in the short and long terms, independent of a comprehensive array of clinical predictors and even when BNP and troponin levels were also included in multivariate analyses.

A recent study has considered the predictive utility of ST2 in a mixed population, not previously studied, with the aim of comparing ST2 and IL-33 concentrations in patients with stable angina (SA) and ACS and subjects without CAD. ${ }^{13}$ Blood samples were taken from 373 consecutive patients with angiographically proved CAD, including 178 with SA, 97 with NSTEMI, and 98 with STEMI. Control subjects were 65 subjects without coronary stenosis on coronary angiography.

ST2 levels were similar in controls (median $0.163 \mathrm{ng} / \mathrm{ml}$, IQR 0.114 to 0.260$)$ and patients with SA $(0.169 \mathrm{ng} / \mathrm{ml}$, IQR 0.079 to 0.260$)(\mathrm{p}=0.34)$. Levels were highest in patients with STEMI $(0.453 \mathrm{ng} / \mathrm{ml}, \mathrm{IQR} 0.313$ to 0.688$)$ compared with those with NSTEMI $(0.269 \mathrm{ng} / \mathrm{ml}$, IQR 0.157 to 0.496 ), those with SA, and controls. ST2 levels were not associated with $\mathrm{CV}$ risk factors such as age, gender, hypertension, family history of CAD, smoking, hyperlipidemia, or diabetes but were correlated positively with creatinine levels. IL-33 was detectable in 58.5\%, $42.4 \%, 46.8 \%$, and $43.6 \%$ of subjects without CAD and patients with SA, NSTEMI, and STEMI, respectively, and serum levels did not differ between groups.

Over a mean follow-up period of 43 months, 37 patients (10\%) died, and the combined end point (death, MI, and readmission for cardiac cause) occurred in 66 patients $(17.6 \%)$. ST2 was higher in those who died than in survivors 

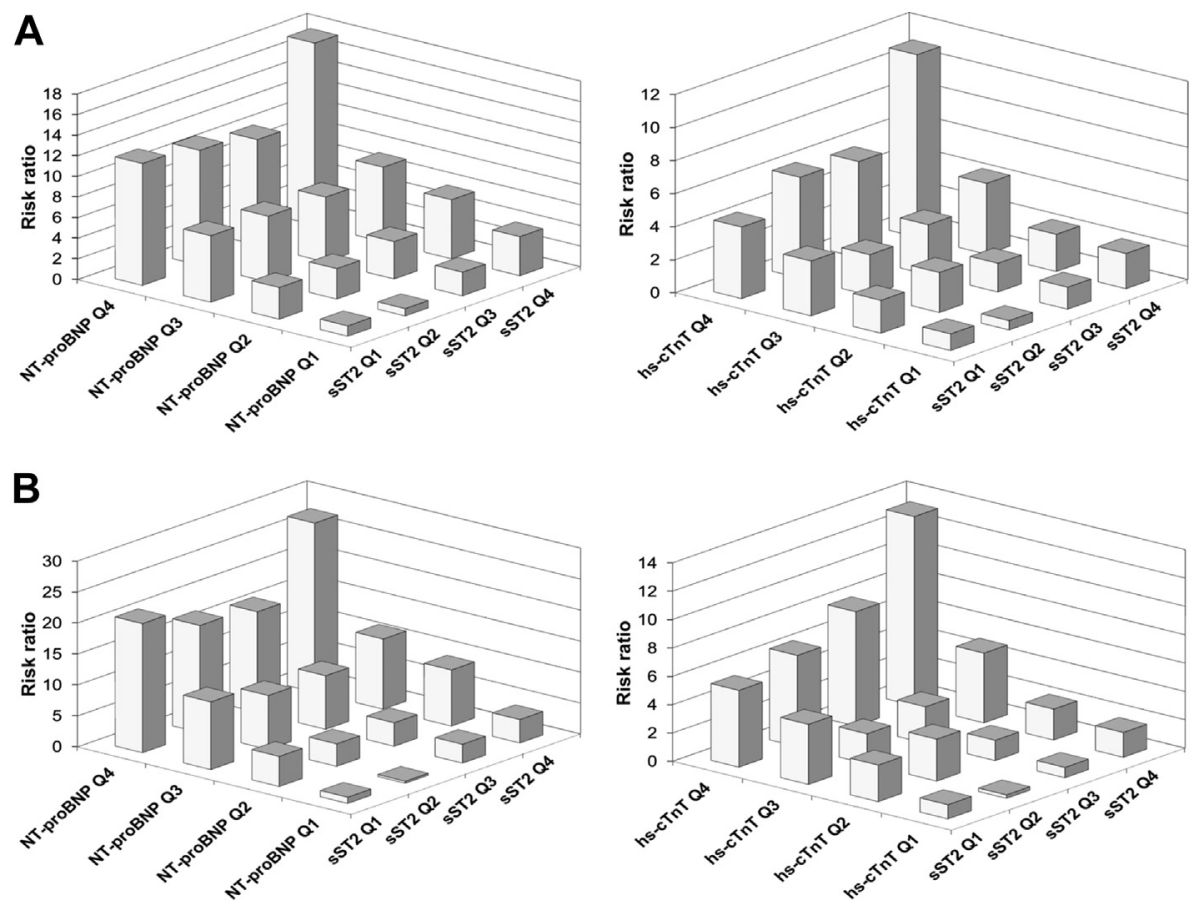

Figure 3. Risk ratios of all-cause mortality $(A)$ and CV mortality $(B)$ in patients with stable CAD for ST2 in addition to NT-proBNP and high-sensitivity cTnT. ST2 quartiles: Q1 <15.6 ng/ml, Q2 15.6 to $19.3 \mathrm{ng} / \mathrm{ml}$, Q3 >19.3 to $24.6 \mathrm{ng} / \mathrm{ml}$, Q4 > $24.6 \mathrm{ng} / \mathrm{ml}$; NT-proBNP quartiles: Q1 <113 ng/L, Q2 113 to $294 \mathrm{ng} / \mathrm{L}$, Q3 $>294$ to $874 \mathrm{ng} / \mathrm{L}, \mathrm{Q} 4>874 \mathrm{ng} / \mathrm{L}$; high-sensitivity cTNT quartiles: Q1 $<6 \mathrm{ng} / \mathrm{L}, \mathrm{Q} 26$ to $10 \mathrm{ng} / \mathrm{L}, \mathrm{Q} 3>10$ to $19 \mathrm{ng} / \mathrm{L}, \mathrm{Q} 4>19 \mathrm{ng} / \mathrm{L}$. ${ }^{15}$

(0.415 ng/ml [IQR 0.136 to 1.158$]$ vs $0.241 \mathrm{ng} / \mathrm{ml}[\mathrm{IQR}$ 0.129 to 0.426$], \mathrm{p}<0.05)$. The highest quintile of soluble ST2 serum levels significantly predicted mortality in the total cohort. When the cohort was stratified according to clinical presentation, ST2 was a strong predictor of mortality in patients with STEMI $(\mathrm{p}<0.001)$ but not in those with NSTEMI or SA. ST2 serum levels significantly predicted the occurrence of the combined end point in patients with STEMI $(\mathrm{p}<0.005)$ and patients with SA $(\mathrm{p}<0.05)$ but not in those with NSTEMI. Multivariate analysis for the population overall (adjusted for age, gender, hyperlipidemia, hypertension, smoking, body mass index, and serum creatinine) indicated that the top quintile of ST2 serum levels was an independent predictor of mortality (HR 2.2, 95\% CI 1.1 to $4.4, \mathrm{p}=0.03$ ). This study indicates a gradient in circulating ST2 from control and SA (which do not differ) to NSTEMI patients, with the highest levels found in those with STEMI. In this mixed population with a relatively small sample size, ST2 was related to death and combined end points over prolonged follow-up. These associations were strongest for STEMI.

\section{ST2 in Stable Coronary Artery Disease}

Our understanding of ST2 in chronic stable coronary disease has been advanced by observations in a sizable cohort of patients who underwent long-term follow-up in the Ludwigshafen Risk and Cardiovascular Health Study. ${ }^{14,15}$
Dieplinger et $\mathrm{al}^{15}$ measured plasma ST2 plasma in 1,345 patients with stable CAD referred for coronary angiography at a single center. The study group included 1,008 men (75\%) and 337 women (25\%), with a median age of 65 years. Two hundred twenty-nine (17\%) had $\geq 1$ stenosis between $20 \%$ and $49 \%$, and 323 (24\%) had 1-vessel, 300 (22\%) 2-vessel, and 493 (37\%) 3-vessel disease. As expected, CV risk factors and $\mathrm{CV}$ medication were highly prevalent. The cohort included 129 patients with HF, including $60(47 \%)$ in New York Heart Association functional class II, $59(46 \%)$ in class III, and $10(7.8 \%)$ in class IV.

ST2 was not correlated with the angiographic severity of CAD $(r=0.038, p=0.159)$.

The primary end point was all-cause mortality. During a median follow-up time of 9.8 years, 477 patients $(36 \%)$ died. The median ST2 plasma concentration at baseline was significantly higher in subsequent decedents than in survivors $(21.4$ vs $18.5 \mathrm{ng} / \mathrm{ml}, \mathrm{p}<0.001)$. The third-quartile value of ST2 was $24.6 \mathrm{ng} / \mathrm{ml}$. In univariate analysis, ST2 in patients with ST2 $>24.6 \mathrm{ng} / \mathrm{ml}$ had a twofold increased risk for death, with risk ratios of 2.01 (95\% CI 1.74 to 2.53, $\mathrm{p}<0.001)$ for all-cause mortality and 2.19 (95\% CI 1.73 to $2.76, \mathrm{p}<0.001$ ) for CV mortality, subsequently attenuated but remaining significant on multivariate analysis (1.39 [9\% CI 1.10 to $1.76, p<0.006$ ] for all-cause mortality and 1.44 [95\% CI 1.08 to $1.93, \mathrm{p}=0.013$ ] for $\mathrm{CV}$ death) after adjustment for clinical variables (gender, age, body mass index, hypertension, dyslipidemia, diabetes, smoking status, 
previous MI, peripheral artery disease, cerebrovascular disease, heart rate, the LVEF, and eGFR) and biomarkers (high-sensitivity CRP, IL-6, NT-proBNP, high-sensitivity cTnT, and Galectin-3).

Receiver-operating characteristic curve analyses for ST2 and mortality at 2 years $(\mathrm{n}=108$ [8\%]), 5 years $(242$ [18\%]), and 9.8 years (477 [36\%]) gave the highest AUC at 2 years $(0.69)$, reducing to 0.64 at 5 years and lowest after 9.8 years at 0.61 . In multivariate Cox proportional-hazards regression analysis, ST2 was an independent predictor of all-cause mortality (risk ratio per 1-SD increase in logtransformed values $1.16,95 \%$ CI 1.05 to $1.29, \mathrm{p}<0.004)$. In the same multivariate analysis, NT-proBNP and highsensitivity cTnT were also independent predictors, whereas galectin-3 was not. ST2 in the highest quartile $(>24.6 \mathrm{ng} / \mathrm{ml})$ was associated with a twofold increased risk for death in univariate analysis that remained significant in the adjusted model $(1.39,95 \%$ CI 1.10 to $1.76, \mathrm{p}<0.006)$.

Hence, ST2 generally within the normal range (thirdquartile value of $24.6 \mathrm{vs}$ about $35 \mathrm{ng} / \mathrm{ml}$ in the early post-MI setting) had prognostic impact additive to NT-proBNP and high-sensitivity cTnT, suggesting possible value from a multimarker approach. Accordingly, risk was highest in patients in the highest quartiles of ST2 and NT-proBNP, as well in the highest quartiles of both ST2 and high-sensitivity cTnT for all-cause and CV mortality (Figure 3).

\section{ST2 and Left Ventricular Remodeling in Ischemic Heart Disease}

Data relating circulating ST2 to cardiac structure and function are relatively sparse and variable, with a number of reports documenting a weak inverse relation between ST2 and the LVEF in varied CV disease cohorts.

Weir et $\mathrm{al}^{16}$ inspected this issue in depth, seeking to assess the relation between ST2 and serial change in LV function after AMI. ST2 levels were measured at baseline and at 12 and 24 weeks in 100 patients (mean age $58.9 \pm 12.0$ years, $77 \%$ men) admitted with AMI with resultant LV systolic dysfunction. Patients underwent cardiac magnetic resonance imaging and measurement of NT-proBNP, norepinephrine, and aldosterone at each time point. Median ST2 decreased from $0.2633 \mathrm{ng} / \mathrm{ml}$ at baseline to $0.1400 \mathrm{ng} / \mathrm{ml}$ at 24 weeks ( $<<0.001)$. ST2 was correlated significantly and inversely with the LVEF at baseline $(\mathrm{r}=-0.30, \mathrm{p}<0.002)$ and 24 weeks $(\mathrm{r}=-0.23, \mathrm{p}=$ 0.026 ); change in ST2 was correlated with change in LV end-diastolic volume index $(\mathrm{r}=-0.24, \mathrm{p}<0.023)$. These correlations were of modest strength only and consistent with previous reports. ST2 was positively associated with infarct volume index at baseline $(\mathrm{r}=0.26, \mathrm{p}<0.005)$ and at 24 weeks $(\mathrm{r}=0.22, \mathrm{p}<0.037)$ and with change in infarct volume index $(\mathrm{r}=0.28, \mathrm{p}<0.001)$. Higher ST2 was associated with greater infarct transmurality and endocardial extent and the presence of microvascular obstruction. ST2 was correlated significantly with norepinephrine and aldosterone but not with NT-proBNP.

ST2 levels early after AMI are related to medium-term changes in LV structure and function. Early postinfarction ST2 is related to infarct size and LV remodeling and may be of pathophysiologic importance in these processes.

\section{Future Perspectives and Unanswered Questions}

It remains unclear what the appropriate ST2 upper reference limit for predicting risk in patients with suspected or proved ACS would be; data from MERLIN-TIMI 36 suggest that the conventional value of $35 \mathrm{ng} / \mathrm{ml}$ might be acceptable, but whether gender-based thresholds might be considered is not conclusively known. The timing of sampling requires further clarity. To the extent that studies repeatedly show superiority of earlier ST2 measures implies that in contrast to data for NT-proBNP (for which values later in hospitalization provide superior prognostic information to baseline in the setting of AMI), earlier measures for ST2 appear most important.

\section{Summary}

Circulating ST2 is related to risk for all-cause and CV death and to $\mathrm{HF}$ in patients with undifferentiated chest pain as well as in those with confirmed IHD, including STEMI, NSTEMI, and chronic stable CAD. Although generally higher in older patients and in those with diabetes, it is far less obviously correlated with many traditional $\mathrm{CV}$ risk factors (such as previous $\mathrm{MI}$ or $\mathrm{HF}$, a poor LVEF, hypertension, and reduced eGFR) than NT-proBNP or highsensitivity troponin $\mathrm{T}$, presumably reflecting distinct pathways for stimulus and secretion.

ST2 has little diagnostic utility in chest pain, but it is independently prognostic across the spectrum of IHD. This is most reliably observed in STEMI and in large cohorts followed for long periods. Early postinfarction ST2 levels have the greatest prognostic power, and samples for this purpose should be acquired as early as possible after presentation, as most of the prognostic signal is lost $>24$ hours the onset of symptoms. Most of the risk conferred by ST2 levels is confined to those with plasma ST2 in the top quartile. About half of patients with MI exhibit early postinfarction ST2 greater than the normal range, and in those with values in the top quartile (generally higher than about $35 \mathrm{ng} / \mathrm{ml}$ ), risk for short- and long-term CV death and HF is doubled after adjustment for clinical factors and for other biomarkers. In stable patients with chronic IHD, the thirdquartile value is about $25 \mathrm{ng} / \mathrm{ml}$, and risk ratios for those with ST2 higher than this cut point are similar to those observed for a cut point of about $35 \mathrm{ng} / \mathrm{ml}$ in ACS settings (albeit with lower absolute event rates). There is consistent and striking improvement in risk stratification when ST2 and BNP are combined. Whether routine measurement of 
ST2 either alone or as part of a multimarker strategy can facilitate improved management and outcomes in IHD remains unknown and requires further investigation.

\section{Author Disclosures}

Dr. Richards has received travel support, speaking fees, research grants, and/or consultancy fees from Roche Diagnostics, Alere, Critical Diagnostics, and Novartis. Dr. Di Somma has received travel support, speaking fees, research grants, and/or consultancy fees from BG Medicine, Biomerieux, Alere, Adrenomed, Sphingotec, ThermoFisher, Critical Diagnostics, Cardiorentis, and Novartis.

1. Schmitz J, Owyang A, Oldham E, Song Y, Murphy E, McClanahan TK, Zurawski G, Moshrefi M, Qin J, Li X, Gorman DM, Bazan JF, Kastelein RA. IL-33, an interleukin-1-like cytokine that signals via the IL-1 receptor-related protein ST2 and induces T helper type 2-associated cytokines. Immunity 2005;23:479-490.

2. Weinberg EO, Shimpo M, De Keulenaer GW, MacGillivray C, Tominaga S, et al. Expression and regulation of ST2, an interleukin-1 receptor family member, in cardiomyocytes and myocardial infarction. Circulation 2002;106:2961-2966.

3. Seki K, Sanada S, Kudinova AY, Steinhauser ML, Handa V, Gannon J, Lee RT. Interleukin-33 prevents apoptosis and improves survival after experimental myocardial infarction through ST2 signaling. Circ Heart Fail 2009;2:684-691.

4. Brown AM, Wu AHB, Clopton P, Robey JL, Hollander JE. ST2 in emergency department chest pain patients with potential acute coronary syndromes. Ann Emerg Med 2007;50:153-158.

5. Aldous SJ, Richards AM, Troughton R, Than M. ST2 has diagnostic and prognostic utility for all-cause mortality and heart failure in patients presenting to the emergency department with chest pain. J Card Fail 2012;18:304-310.

6. Shimpo M, Morrow DA, Weinberg EO, Sabatine MS, Murphy SA, Antman EM, Lee RT. Serum levels of the interleukin-1 receptor family member ST2 predict mortality and clinical outcome in acute myocardial infarction. Circulation 2004;109:2186-2190.
7. Sabatine MS, Morrow DA, Higgins LJ, MacGillivray C, Guo W, Bode C, Rifai N, Cannon CP, Gerszten RE, Lee RT. Complementary roles for biomarkers of biomechanical strain ST2 and N-terminal prohormone B-type natriuretic peptide in patients with ST-elevation myocardial infarction. Circulation 2008;117:1936-1944.

8. Dhillon OS, Narayan HK, Khan SQ, Kelly D, Quinn PA, Squire IB, Davies JE, Ng LL. Pre-discharge risk stratification in unselected STEMI: is there a role for ST2 or its natural ligand IL-33 when compared with contemporary risk markers? Int J Cardiol 2013;167: $2182-2188$

9. Granger CB, Goldberg RJ, Dabbous O, et al. Global Registry of acute coronary events investigators. Predictors of hospital mortality in the global registry of acute coronary events. Arch Intern Med 2003;163: 2345-2353.

10. Eggers KM, Armstrong PW, Califf RM, Simoons ML, Venge P, Wallentin L, James SK. ST2 and mortality in non-ST-segment elevation acute coronary syndrome. Am Heart J 2010;159:788-794.

11. Dhillon OS, Narayan HK, Quinn PA, Squire IB, Davies JE, Ng LL. Interleukin 33 and ST2 in non-ST-elevation myocardial infarction: comparison with Global Registry of Acute Coronary Events risk scoring and NT-proBNP. Am Heart J 2011;161:1163-1167.

12. Kohli P, Bonaca MP, Kakkar R, Kudinova AY, Scirica BM, Sabatine MS, Murphy SA, Braunwald E, Lee RT, Morrow DA. Role of ST2 in non-ST-elevation acute coronary syndrome in the MERLIN-TIMI 36 trial. Clin Chem 2012;58:257-266.

13. Demyanets S, Speidl WS, Tentzeris I, Jarai R, Katsaros KM, Farhan S, Krychtiuk KA, Wonnerth A, Weiss TW, Huber K, Wojta J. Soluble ST2 and interleukin-33 levels in coronary artery disease: relation to disease activity and adverse outcome. PLoS ONE 2014;9:e95055.

14. Winkelmann BR, März W, Boehm BO, Zotz R, Hager J, Hellstern P, et al. Rationale and design of the LURIC study: a resource for functional genomics, pharmacogenomics and long-term prognosis of cardiovascular disease. Pharmacogenomics 2001;2:S1-S73.

15. Dieplinger B, Egger M, Haltmayer M, Kleber ME, Scharnagl H, Silbernagel G, de Boer RA, Maerz W, Mueller T. Increased soluble ST2 predicts long-term mortality in patients with stable coronary artery disease: results from the Ludwigshafen Risk and Cardiovascular Health Study. Clin Chem 2014;60:530-554.

16. Weir RAP, Miller AM, Murphy GEJ, Clements S, Steedman T, Connell JMC, McInnes IB, Dargie HJ, McMurray JJV. Serum soluble ST2: a potential novel mediator in left ventricular and infarct remodeling after acute myocardial infarction. J Am Coll Cardiol 2010;55:243-250. 